\title{
The supervised community treatment order and the Human Rights Act $1998^{\dagger}$
}

\author{
Sanjay Khurmi \& Martin Curtice
}

\begin{abstract}
SUMMARY
The introduction of the supervised community treatment order (CTO) was a major and significant change to the Mental Health Act 1983 following the 2007 amendments to the Act. Owing to paternalistic aspects of psychiatry, such new legislation brings with it the potential to impinge on the human rights of patients. Any new legislation must be read and implemented to be compliant with the Human Rights Act 1998. Of all the articles comprising the Human Rights Act, Article 3 (the right to freedom from inhuman and degrading treatment), Article 5 (the right to liberty and security) and Article 8 (the right to respect for family and private life, home and correspondence) are of particular relevance to CTOs. We consider here the potential implications of the use of CTOs with regard to the Human Rights Act.
\end{abstract}

\section{DECLARATION OF INTEREST}

None.

The Human Rights Act 1998 enacts most of the European Convention on Human Rights into UK law. It is UK statute, enforceable by courts and tribunals, including mental health tribunals, and sets out fundamental rights that all people are entitled to enjoy. Courts and mental health tribunals are obliged to interpret the Mental Health Act 1983 consistently with the Human Rights Act. The Human Rights Act thus has the effect of bringing human rights to the centre of both legal and health systems (Department of Health 2008a). The European Convention on Human Rights has a number of articles which influence psychiatric practice. These include the rights to life (Article 2; Curtice 2009a), freedom from inhuman and degrading treatment (Article 3; Curtice 2008), liberty and security (Article 5), a fair trial (Article 6) and private life (Article 8; Curtice 2009b). Seminal and benchmark European Convention case law provided by Winterwerp v. The Netherlands [1979], Bournewood (HL v. UK 2004) and Herczegfalvy v. Austria (1992) has heavily influenced UK practice in respect of detention of the mentally ill, deprivation of liberty of incapacitous patients (Article 5) and freedom of correspondence (Article 8) respectively. The European Convention on Human Rights is a 'living instrument which must be interpreted in light of present-day conditions' (Tyrer v. UK 1978). Therefore case law, being a dynamic process, will continuously evolve over time and will in the future clarify how the European Convention on Human Rights has an impact (or not) on mental health law and psychiatric care in the UK.

Of all the changes made under the 2007 amendments to the Mental Health Act (Office of Public Sector Information 2007), the introduction, in Section 17A, of the supervised community treatment order (CTO) was arguably the most significant. Human rights have a close relationship with mental health policy and particularly with CTOs. Community treatment orders can have both positive and negative effects on human rights through the compulsory detention of patients. Patients often face stigma and discrimination because of their abnormal mental state and for spending often protracted periods in hospital, and may be unable to fully exercise their human rights to respect, equality and autonomy. Community treatment orders can help these vulnerable individuals regain their rights through treatment in the community. Conversely, if these orders are used inappropriately or overzealously (as may happen with the introduction of brand new legislation) or if the conditions are too restrictive, this can have a significant negative impact on a patient's human rights and consequently their wellbeing. It can lead to loss of autonomy and dignity, promote discrimination and increase mental suffering (Goldfeld 1988; Hendriks 1995; Neufeldt 1995). Will increased restriction of patient's rights and liberty be balanced by better quality of life? Striking the right balance can be a difficult task for the clinician but they can be aided by using a proportionality approach towards human rights issues (Box 1). Striking the right balance requires adequate legal safeguards and these are provided by the Human Rights Act 1998 and the 2007 amendments to the Mental Health Act 1983.

ARTICLE

Sanjay Khurmi is a locum consultant in general adult psychiatry. He obtained a Master of Laws with Commendation in Mental Health Law in 2009 and has a continuing interest in mental health law. He sits on the Royal College of Psychiatrists' Special Committee on Human Rights. Martin Curtice is a consultant in old age psychiatry. He obtained a Master of Laws with Distinction in Mental Health Law in 2003 and has an interest in mental health law and the Human Rights Act 1998. He sits on the Royal College of Psychiatrists' Special Committee on Human Rights. Correspondence Dr Sanjay Khurmi, Coventry and Warwickshire Partnership Trust, Crisis Resolution Home Treatment Team, Swanswell Point, Swanswell Road, Coventry CV1 4FH, UK. Email: skhurmi@ hotmail.com

'See also pp. 245-252, 253-259 and 260-262, this issue. 
BOX 1 Approaches to human rights issues and proportionality within mental health tribunals and reports

- Consider the objective of the order and why it is needed - for in-patients, it may be to organise an appropriate placement so that risks to health can be minimised or further treatment given to help the patient gain insight

- Consider the potential negatives of the order (e.g. restrictions on the patient's Article 3,5 and 8 human rights caused by an order)

- Consider the potential benefits of the order (e.g. to prevent deterioration of health, for the protection of others)

- Consider alternatives to the obvious - in a report, it might be explained that, of a series of listed options, the option chosen was considered to be the most proportional and least restrictive
- Always aim for the most least restrictive option(s), however complex the case

- Outline why, after considering the competing interests, you believe it is a proportionate measure - within this process, consideration and explanation of the patient's ability to consent or not to treatment would also be important

- Include a specific statement in a mental health tribunal report about the proportionality of continued compulsory detention

- Use specific historical information from the patient's past history when using a proportionality-based approach to justify continued compulsory detention (e.g. poor adherence to treatment often leading to relapses and/or admission)
We explore here rights offered under Articles 3, 5 and 8 of the Human Rights Act which are pertinent to individuals subject to CTOs; consider the compatibility between the Mental Health Act and the Human Rights Act for CTOs; and consider whether the Human Rights Act might provide any added legal safeguards for patients on CTOs.

\section{Article 3}

Article 3 of the Human Rights Act states that 'No one shall be subjected to torture or to inhuman or degrading treatment or punishment'. It is an absolute right and does not allow for any exemptions even if these are considered necessary for the public's health, safety or national security (Ribitsch v. Austria 1995). The terms inhuman and degrading have been defined by seminal case law (Box 2). For an in-depth review of Article 3 mental health case law in Advances, see Curtice (2008).

\section{Pertinent Article 3 case law}

Herczegfalvy v. Austria (1992)

This has become the benchmark case with respect to Article 3 and psychiatric treatment. Mr Herczegfalvy argued that the forcible administration of antipsychotic medication, of being force-fed, and at times being secured to a bed was inhuman and degrading, hence an infringement of his Article 3 rights. The judgment opined that medical treatment deemed to be therapeutically necessary and for which need had been convincingly shown to exist could not be deemed inhuman or degrading irrespective of the individual's capacity to consent. Even though Mr Herczegfalvy had incurred various injuries while being forcibly restrained, the European Court did not find a violation of Article 3 because the treatment he had received had been consistent with accepted clinical practice at that time.

\section{Keenan v. UK [2001]}

This case concerned a 28-year-old man detained in Exeter prison. He had a history of schizophrenia, personality disorder and self-harm, but was found to be fit for segregation after he assaulted two prison officers. While segregated, Mr Keenan hanged himself. Although accepting that segregation did not normally breach Article 3, his mother appealed, claiming that his treatment had been inhuman and degrading.

The court noted that authorities are obliged to protect the health of persons deprived of their liberty by providing requisite medical care (Hurtado v. Switzerland 1994; see also Kucheruk v. Ukraine 2007; Pilcic v. Croatia 2008; Musiał v. Poland 2009). This was particularly pertinent to this case as there was a lack of medical notes documenting care and insufficient psychiatric assessment. Primarily for the reason of substandard care, the court found that there had been a violation of Article 3 because the (lack of) treatment received constituted inhuman treatment.

\section{Article 3 and community treatment orders}

Could the imposition of a CTO and its associated conditions be considered degrading treatment? Under the 2007 amendments to the Mental Health

\section{BOX 2 Definitions of treatment under Article 3}

\section{Degrading treatment}

Where treatment humiliates or debases an individual, shows lack of respect for or diminishes their human dignity, or arouses feelings of fear, anguish or inferiority capable of breaking their moral and physical resistance, it may be characterised as degrading (Pretty v. UK 2002).

\section{Inhuman treatment}

Treatment could be construed as inhuman if it causes intense physical or mental suffering in the patient (Ireland v. UK [1978]).

\section{III treatment}

Case law has further elucidated that ill treatment must attain a minimum level of severity if it is to fall within the scope of Article 3. The assessment of this minimum is relative and depends on all the circumstances of the case, such as the duration of the treatment, its physical or mental effects and, in some cases, the gender, age and state of health of the victim (Ireland $v$. UK [1978]). 
Act, the definition of 'medical treatment' is very wide, including many forms of treatment and conditions ordered under CTOs (Sections 145(1) and 145(4)).

Dignity is a key component of the definition of degrading. Case law has confirmed that in the case of physical force that 'has not been made strictly necessary', it 'diminishes human dignity and is in principle an infringement of the right set forth in Article 3' (Ribitsch v. Austria 1995). Although recourse to such force is unlikely under the conditions of a CTO, these orders have the potential to have a negative effect on an individual's sense of autonomy and dignity. The prospect of having conditions imposed on where they can live, what they can do (e.g. the need to abstain from alcohol/ cannabis) and where they can go could cause the public to have less respect for, or to stigmatise, patients on CTOs, causing in them feelings of inferiority and/or anguish. Although unlikely, it is theoretically possible that a CTO could result in negative effects of sufficient severity to be regarded as degrading and thus a violation of Article 3.

Article 3 case law appears to have been highly deferential to mental health professionals (Gostin 2000) and sets a very high threshold for violation. This makes it unlikely that a 'routine' CTO would infringe a patient's Article 3 rights. As long as treatments are thought to be therapeutically necessary and conform to accepted psychiatric principles, an Article 3 CTO case is unlikely to succeed. Although still providing important protection from severe maltreatment to capacitous and incapacitous patients alike, Article 3 will not seemingly confer any additional specific protection to patients under CTOs.

\section{Article 5}

Article 5 of the Human Rights Act protects the right of liberty and security (Box 3). It is the only article of the Act that specifically mentions 'persons of unsound mind', which is taken to mean mental disorder (Winterwerp v. The Netherlands [1979]). It is under Article 5(1)(e) that detention on account of unsoundness of mind is allowed. Important challenges in the UK using Article 5(1)(e) have led to clarification of the legal definition of detention (Ashingdane v. UK 1985) and with whom the burden of proof lies in a mental health tribunal hearing $(R(H) v$. Mental Health Tribunal (North and East London) [2002]).

Article 5(4) is also of particular relevance to CTOs. Successful challenges to UK practice using Article 5(4) rights have occurred because of the lack of 'speed' of mental health tribunal review of detention ( $R(K B$ and others) v. Mental Health Tribunal [2002]; Kolanis v. UK 2005).
BOX 3 Key Article 5 rights relating to community treatment orders
Article 5(1)(e)

Everyone has the right to liberty and security of person. No one shall be deprived of his liberty save in the following cases and in accordance with a procedure prescribed by law: the lawful detention of persons ... of unsound mind
Article 5(4)

Everyone who is deprived of their liberty by arrest or detention shall be entitled to take proceedings by which the lawfulness of his detention shall be decided speedily by a court and his release ordered if his detention is not lawful.
Patients may challenge the imposition of a CTO through a mental health tribunal, but they are unable specifically to challenge the conditions attached to the order. However, it may be the conditions rather than the actual order to which they object. The lack of legal recourse to challenge conditions could leave patients with little protection against overzealous but well-meaning professionals. This important issue is considered with regard to Article 5.

\section{Deprivation of liberty or restriction of movement?}

For a patient on a CTO to have the protections offered by Article 5, they have to be legally deprived of their liberty. If the Human Rights Act deems that a CTO with conditions meets the legal criteria that make it a deprivation of liberty the patient must have the right to challenge these conditions through a mental health tribunal. Without this right, the CTO would be incompatible with the Human Rights Act. The question of whether a patient is deprived of their liberty is crucial. If a CTO with conditions does not meet the criteria for deprivation of liberty but is rather deemed a 'restriction of movement', weaker safeguards would be offered by Article 2 from Protocol 4 of the European Convention on Human Rights (the right to liberty of movement), but this does not include recourse to 'speedy' review by a court.

\section{The meaning of deprivation of liberty}

The issue of whether a patient has been deprived of their liberty for the purposes of Article 5(1) has been determined by a series of cases in the European Court of Human Rights (Nielsen v. Denmark 1988; HM v. Switzerland 2002; HL v. UK 2004; Storck v. Germany 2005). The dividing line between deprivation of liberty and restriction of movement is fine and not easy to determine. The classic statement as to the meaning of deprivation of liberty, found in Guzzardi v. Italy (1980), demonstrates this complexity:

In order to determine whether someone has been

'deprived of his liberty' within the meaning of Article

5 , the starting point must be his concrete situation 
and account must be taken of a whole range of criteria such as the type, duration, effects and manner of implementation of the measure in question ... the difference between deprivation of and restriction upon liberty is nonetheless merely one of degree or intensity, and not one of nature or substance.

The judgment of Storck v. Germany (2005) revealed three essential elements to the deprivation of the plaintive's liberty: the objective and subjective elements, and the requirement that the deprivation of liberty be due to state responsibilities. It is clear that the CTO will satisfy the last criterion, but what of the other two?

\section{The objective element}

According to the Guzzardi judgment there is a sliding scale of severity of restriction: restriction of movement lies at one end of the scale and detention lies at the other. The key factor is whether the person is free to leave. Two influential UK cases have helped clarify the boundaries of deprivation of liberty.

The seminal HL v. UK(2004) ('Bournewood') case determined that complete and effective control over the care of an incapacitous person who adhered to medication was a violation of Article 5 as it met the requirements for deprivation of liberty. Under the common law doctrine of necessity, the absence of procedural safeguards against arbitrary detention and access to the court amounted to a breach of Articles 5(1) and 5(4). This was the catalyst for the introduction of deprivation of liberty safeguards

${ }^{\dagger}$ Nick Brindle \& Tim Branton will discuss the deprivation of liberty safeguards in relation to the Mental Capacity Act and the Mental Health Act in a future issue of Advances. Ed. legislation in England and Wales ${ }^{\dagger}$ to ensure that the Mental Capacity Act 2005 is compliant with the Human Rights Act.

The case of $J E$ v. DE \& Ors [2006] involved a 76-year-old man with dementia who was placed in residential care by the local authority. He was assessed to lack capacity and found to be deprived of his liberty under Article 5. This was despite the fact that he was allowed to leave the home on planned trips and was not in a locked unit (the judgment noted, however, that whether a patient is kept in 'locked' or 'open' conditions is not determinative). The judgment found that the Council had deprived him of his liberty as he was not free to leave alone. This was evidenced by his repeated verbalised wish to return home and live with his wife, by the fact that he was not allowed to go out on unplanned trips alone and by the threat of police involvement if his wife attempted to take him from the home.

Because the current definition is imprecise, deprivation of liberty is decided on a case-by-case basis, and therefore it does not prove conclusively that a CTO could not lead to a person's deprivation of liberty.

\section{The subjective element}

The subjective element is determined by capacity and consent. Valid consent is determined by the patient having capacity. There is no deprivation of liberty if a capacitous patient consents or does not object to their confinement. However, if they refuse consent, this will satisfy the subjective element of deprivation of liberty. If a patient without capacity resists, this will be taken to be a strong indicator that this element is satisfied, but it is not determinative.

\section{Community treatment orders and deprivation of liberty}

It appears that a CTO could with little difficulty satisfy the subjective element of a patient being deprived of their liberty. Many patients with capacity will feel that a CTO is unnecessary and object to the placement of the order or its conditions (akin to treatment under Section 58 of the Mental Health Act and the capacitous but refusing detained patient (R(PS) v. (1) Dr G and (2) Dr W [2003]) and Section 63 (treatment not requiring consent; Curtice 2002). Similarly, incapacitous patients may undertake action(s) that suggest they object and may make requests to break the conditions.

Whether a CTO would satisfy the objective element is more complex. Patients would not be locked in a ward, although as noted earlier this is not determinative. Case law suggests that each case needs to be assessed on the individual facts. Although likely to be rare in occurrence, because under Section 17B of the Mental Health Act any number of conditions can be applied to a CTO, there could be a constellation of conditions that were so widespread yet overly stringent as to be construed a deprivation of liberty.

However, as noted above, any such cases would have no recourse, via a mental health tribunal, to challenge actual conditions attached to the CTO. If the conditions did cause deprivation of liberty, a patient would have the protections offered by Article 5(4). These requirements could be offered by judicial review and habeas corpus proceedings (Box 4), although they have the potential to be

BOX 4 Judicial review and habeas corpus

Judicial review is a type of court proceeding in which a judge reviews the lawfulness of a decision or action made by a public body

Habeas corpus comprises an order requiring a person to be brought before a judge or into court, especially to secure that person's release unless lawful grounds are shown for their detention 
legally challenged themselves. The epoch-making $H L$ v. UK case concluded that judicial review and habeas corpus proceedings did not satisfy Article 5(4), which therefore was violated (i.e. such practice was insufficient to review relevant medical decisions and did not provide adequate means to challenge a deprivation of liberty). Box 5 outlines the requirements of a review that satisfy Article 5(4).

The introduction of the Human Rights Act may change the manner of these reviews and future legal challenges will demonstrate whether they are sufficient or not. Deprivation of liberty safeguards could provide a review of incapacitous patients while on a CTO but do not offer safeguards for capacitous mentally ill patients (deprivation of liberty under the Mental Capacity Act 2005 can exist alongside supervised community treatment or leave of absence, provided that there is no conflict with the conditions of supervised community treatment or leave of absence set by the patient's responsible clinician) (Department of Health 2008b: paras. 28.7-28.10).

Irrespective of the legality of these courts and proceedings, they are not the most appropriate forum for patients with mental illness. They are not as accessible, flexible or patient friendly as mental health tribunals, which may deter many patients. It is unfortunate that the government chose not to allow challenges to conditions through mental health tribunals, as this would have provided an easily accessible safeguard for patients.

\section{Article 8}

Article 8 of the Human Rights Act prohibits public authorities from interfering with a person's right 'to respect for his family and private life, his home and correspondence.' It consists of two parts:

- Article 8(1): everyone has the right to respect for his private and family life, his home and his correspondence;

- Article 8(2): there shall be no interference by a public authority with the exercise of this right except such as is in accordance with the law and is necessary in a democratic society in the interests of national security, public safety or the economic well-being of the country, for the prevention of disorder or crime, for the protection of health or morals, or for the protection of the rights and freedoms of others.

It is a qualified right, and therefore interferences with it are permissible if they satisfy requirements outlined in Article 8(2). Such exceptions are permitted only when in 'accordance with law' and when they are 'necessary in a democratic society'
BOX 5 Characteristics of a lawful review under Article 5(4) from European Convention on Human Rights case law

- A review of lawfulness of the deprivation of liberty is to be available at reasonable intervals (Winterwerp v. The Netherlands [1979])

- The court needs to be independent both of the executive and of the parties to the case (Winterwerp v. The Netherlands [1979])

- The procedure followed in the case is of judicial character and gives to the individual concerned guarantees appropriate to the kind of deprivation of liberty in question (Winterwerp v. The Netherlands [1979])

- The absolute minimum requirement is the right of the individual concerned to present their own case and to challenge the medical and social evidence adduced in support of their detention (Winterwerp v. The Netherlands [1979])

- It is essential that the person concerned should have access to a court and the opportunity to be heard either in person or, where necessary, through some form of representation (Winterwerp v. The Netherlands [1979]

- The review must allow a determination of the merits of the question as to whether the mental disorder persisted (XV. UK 1981)

- The review must be sufficiently intrusive to constitute an adequate examination of the merits of the relevant medical decisions (HL v. UK 2004)

for interests outlined in it. Any interferences must be demonstrated as being proportionate (Nasri v. France 1995), proportionality being a core concept underpinning the Human Rights Act). The implications of Article 8 case law in clinical practice have been reviewed in Advances by Curtice (2009b).

Article 8 has been one of the most dynamically interpreted provisions of the European Convention on Human Rights and has an extremely wide application. However, case law has indicated that Article 8 cannot be considered applicable each time an individual's everyday life has been disrupted and that it applies only in exceptional cases (Sentges v. The Netherlands 2003).

\section{Article 8 case law}

The concept of private and family life includes both the physical and psychological integrity of a person (Bensaid v. UK 2001). The notion of personal autonomy and the right to self-determination are important principles underlying the guarantees offered by Article 8 (Pretty v. UK 2002). Selfdetermination and patient autonomy are protected by Article 8, but the presence or absence of capacity in determining this is less clear.

In Wilkinson v. UK [2006] the applicant complained that the administration of depot antipsychotics against his will violated his Article 3 and 8 rights (see also Grare v. France [1992], where the imposition of antipsychotic drugs, resulting in unpleasant side-effects, did not breach Article 8 because it was justified under Article $8(2)$ to maintain public order and to protect the 
applicant's own health). The court found that there was no Article 8 breach because Wilkinson had not convincingly proved that he had the requisite capacity to refuse treatment. As of yet, no European case has examined whether Article 8 is infringed if treatment is given to a refusing patient with capacity.

UK courts have similarly held that treatment with antipsychotic drugs of a capacitous patient against his will did not breach his Article 3 or 8 rights (R(PS) v. (1) Dr G and (2) Dr W [2003]). Having capacity in such cases should be considered closely but it is not a determinative factor $(R(B) \mathrm{v}$. (1) Dr SS (2) Dr G (3) Secretary of State [2005]). For a review in Advances of case law in this area, see Curtice (2009c).

\section{Community treatment orders and Article 8}

Community treatment orders and the attached conditions have the potential for far-reaching effects on capacitous and incapacitous patients. Section 17B of the Mental Health Act states that any number of conditions can be applied to a CTO provided that they meet Section $17 \mathrm{~B}(2)$ requirements: i.e. they are necessary or appropriate for (a) ensuring that the patient receives medical treatment, (b) preventing risk of harm to the patient's health or safety, and/or (c) protecting other persons. Therefore as long as the conditions satisfy Section $17 \mathrm{~B}(2)$ requirements, they could amount to a responsible clinician dictating a patient's life and living circumstances in the community. Conditions may include avoidance of known risk factors, which may include family members. If conditions forbade family visits or deprived patients of their autonomy or liberty despite family objections, Article 8(1) may well be engaged. Whether such interference constituted a violation of a patient's right to private and family life would depend on it being justified or not under Article 8(2) (i.e. being 'in accordance with the law' and 'necessary in a democratic society').

\section{'In accordance with law'}

This requires that: (a) the law is accessible to the person concerned; (b) the person concerned must be able to foresee the circumstances in which the public authority would be allowed to exercise its power in a particular respect; and (c) domestic law must contain adequate legal protections and 'fair and proper procedures' (Herczegfalvy $\mathrm{v}$. Austria 1992).

Is a CTO 'in accordance with law'? First, CTOs appear to satisfy the accessibility criteria as legislation is published and freely available on the internet. Second, with regard to foreseeability, the statute (i.e. Section 17B(2) and the Mental Health Act Code of Practice) outline the circumstances in which the conditions and recall may be used.

The final requirement, of 'legal protections', has raised debate. The Joint Committee on Human Rights (2007) opined that the additional protection of a hospital manager's endorsement was needed to ensure the 'minimum level of protection' against arbitrariness. Endorsement by an approved mental health professional is currently required to verify a CTO and its attached conditions, but doubts as to the independence of such an individual while working within a multidisciplinary team were also raised.

\section{'Necessary in a democratic society'}

Interference with Article 8(1) rights by a CTO may be lawful and deemed necessary if it pursues the legitimate aim of 'protecting health, morals, or for the protection of the rights and freedoms of others'; the interference must be rationally connected to this aim and the means used to impair the right must be no more than are necessary (proportionate) to accomplish this aim $(R$ v. Secretary of State for the Home Department [2001]).

\section{Is the interference of a community treatment order rationally connected to the aim?}

For an infringement of Article 8 rights to be deemed necessary (proportionate), it must be for a purpose outlined in Article 8(2). It must also be rationally connected to this aim. While investigating individual claims, the European Court of Human Rights will hear evidence and may decide that an intrusion was not rationally connected to a pressing need as outlined in Article 8(2) (Smith \& Grady v. UK 1999). If the European Court were to apply such principles to a CTO case they might find the introduction of the order disproportionate, particularly if the evidence for it is weak or non-existent and not convincingly shown to be rationally connected to the aim. Reviewing relevant evidence relating to CTOs could therefore be considered in some cases.

\section{Community treatment orders and homicides}

The National Confidential Inquiry into Suicide and Homicide by People with Mental Illness (Appleby 2006) found that around 50 homicides a year are committed by psychiatric patients in the community. Eight homicides a year are committed by previously detained patients after non-adherence or loss of contact with services (potential candidates for CTOs). This compares with twice as many homicides committed by mental health patients who had no contact with mental health services 
in the year before the offence. The introduction of CTOs would appear therefore to be unlikely to have much impact on homicides committed by this group of patients.

A review commissioned by the Department of Health suggested that CTOs may not change adherence rates (Churchill 2007). They may have little impact on patients whose non-adherence to medication was thought to be a contributory factor. It could be argued that, overall, CTOs will have little effect on homicides and consequently may have little overall effect on protecting the rights of others.

\section{Community treatment orders being necessary} 'for the protection of health'

Another of the additional aims set out by Article $8(2)$ is for the protection of health, but does the evidence suggest that CTOs would be proportional or connected to aims of protecting health?

A US study suggests that 85 people are required to be on a CTO in order to avoid one admission to hospital (Kisely 2005). A review of CTO use internationally found little evidence of positive effect on hospital readmission rates, length of stay or even adherence to medication (Churchill 2007). Such evidence suggests that the relative effect of a CTO on the legitimate aims set out in Article 8(2) is likely to be minimal at best. It could be argued that the order has questionable benefits for these aims, and the current evidence does not suggest such aims would be rationally connected to available evidence. This of course may change as evidence is accrued from the use of CTOs in the UK.

\section{Necessity and proportionality}

The third aspect of Article 8(2), 'necessary in a democratic society' is a complex issue. The term 'necessary' implies the existence of a pressing social need for the interference in question (Dudgeon $\mathrm{v}$. UK 1981). Thus, for a CTO to lawfully interfere with an Article 8 right, there has to be a clear need for the CTO to occur and the means used must be proportional. Proportionality is a wellestablished principle of the European Convention on Human Rights (De Burca 1993) and is becoming increasingly important within mental health tribunals (especially when assessing conditions attached to a CTO). It is a way of addressing tensions and conflicts between competing claims and rights (i.e. a patient's human rights $v$. the need to protect others, self and health). In practical terms, a proportional decision 'is appropriate and not excessive in the circumstances' and 'the more substantial the interference the more that is required to justify it', i.e. that a sliding scale should be applied $(R(N) v$. (1) Ashworth (2) Secretary of State for Health [2001]). Box 1 outlines an approach to addressing proportionality issues in mental health tribunal reports and during tribunal hearings.

The case of L. v. Sweden (1988) has provided guidance on the proportionality of community treatment. The European Commission held that the decision to provisionally release someone from a psychiatric hospital and place on them a condition to receive treatment on an out-patient basis constituted an interference with their right to respect for private life. However, the Commission went on to declare the application 'manifestly illfounded', holding that the measure was justified in the interests of the person's health under Article 8(2) (interestingly, $L$ had no forensic history of note and the judgment opined that the infringement was necessary for the protection of her health alone). A narrow interpretation of this judgment would imply that the condition of receiving treatment in the community for health purposes alone is a proportional interference with Article 8 rights. A wider interpretation would be that various conditions if placed on a patient for the purposes of the protection of health could be proportional if they fulfil Article 8(2) requirements.

\section{Does a community treatment order meet the requirements of Article 8(2)?}

It appears that a CTO is compatible with Article 8(2), although current UK and European jurisprudence on the matter is limited. It appears that the European Court of Human Rights shows deference to medical opinion without thorough investigation of the proportionality of decisions. It will be interesting to see whether future case law elucidates this issue. Despite this, the doctrine of proportionality may in future provide an important safeguard for patients on CTOs against prolonged infringement of Article 8 rights. Such a safeguard, however, will be dependent on the European Court of Human Rights applying a greater level of scrutiny to the proportionality of decisions than they have done thus far.

As outlined, there is little supporting evidence for using CTOs for the legitimate aims of protecting the public, reducing crime and protection of health. Theoretically, a test case may challenge the restriction of Article 8 rights by a CTO, given its tenuous links to the defined aims. This may force mental health tribunals to take proportionality principles into account and might lower the threshold for discharge from a CTO. Despite this possibility, the present interpretation of Article 8 does not appear to provide CTO patients with any additional safeguards. 
MCO answers

1 e $2 d \quad 3 c \quad 4 c \quad 5 b$

\section{Alternatives to community treatment orders and implications for human rights}

Despite needing to consider a CTO when sending an in-patient on more than 7 days' leave, extended Section 17 leave still remains a viable alternative (Department of Health 2008b). They both have a similar impact on human rights as wide-ranging conditions and the threat of recall to hospital may be applied to both orders. As Section 17 leave is likely to be shorter in duration, as advocated by the Mental Health Act Code of Practice, it will have fewer long-term human rights implications and, if challenged, may be more likely to be viewed as a proportional decision. Guardianship (under Section 7 or 37 of the Mental Health Act) is an alternative to the CTO, buy it applies predominantly to patients whose welfare, not health, is the focus of the treating team. Again, patients under a guardianship order are afforded the same protection under the Human Rights Act as those subject to other sections of the Mental Health Act.

\section{Discussion}

The Human Rights Act ensures that patients' human rights must be considered in domestic mental health law and clinical practice. The Mental Health Act can help vulnerable patients protect their human rights. Conversely, imbalanced mental health policy or its overzealous use can lead to a patient's human rights being taken away. The government has acknowledged that supervised community treatment was a key change in the 2007 amendments to the Mental Health Act and accepts it is an area of controversy (Hansard 2006). However, it has stated the hope that the approach will strike a balance between individual human rights and protection of the patient and public, and will help reduce the risk of social exclusion and stigma associated with long periods of detention in hospital or repeated hospital admissions. Striking the correct balance requires adequate legal safeguards.

Articles 3, 5 and 8 of the Human Rights Act do not appear to offer any significant additional safeguards against prolonged compulsion to those already offered to detained patients. The threshold for violations of Article 3 is set at a high level, making it unlikely that CTOs or treatments given under their remit will violate this right. Protections offered under Article 5 are unlikely to be available to patients on CTOs as they are unlikely to satisfy the legal definition of deprivation of liberty. Article 8 and the doctrine of proportionality do offer some hope, although they provide scant safeguard at present. Overall, the new CTO legislation appears compliant with the Human Rights Act.
Within the UK there are examples of how the European Convention on Human Rights has already offered greater protection of human rights - greater protections for patients subject to restriction orders ( $X v \cdot U K 1981)$, reversal of proof within mental health tribunals and deprivation of liberty safeguards. Although CTOs have been well established in other parts of the world (the USA, Canada, Australia and New Zealand; for a review see Churchill 2007), they are relatively new to Europe (introduced in Scotland in 2005) and hence there is as yet no influential case law. It will be interesting to see whether future CTO case law tests its compliance with the Human Rights Act and in doing so adds further safeguards and protections of patients' human rights.

\section{References}

Appleby, L., Shaw, J., Kapur, N., et al (2006) Avoidable Deaths: Five Year Report by the National Confidential Inquiry into Suicide and Homicide By People with Mental IIIness. University of Manchester (http://www. medicine.manchester.ac.uk/psychiatry/research/suicide/prevention/nci/ england_and_wales).

Churchill R (2007) International Experiences of Using Community Treatment Orders. Institute of Psychiatry (http://www.dh.gov.uk/ prod_consum_dh/groups/dh_digitalassets/documents/digitalasset/ dh_072728.pdf).

Curtice M (2002) Force-feeding: implications for the Mental Health Act 1983 and the Human Rights Act 1998. Journal of Mental Health 11: 235-43.

Curtice M (2008) Article 3 of the Human Rights Act 1998: implications for clinical practice. Advances in Psychiatric Treatment 14: 389-97.

Curtice M, Sandford J (2009a) Article 2 of the Human Rights Act 1998 and the treatment of prisoners. Advances in Psychiatric Treatment 15: $444-50$

Curtice M (2009b) Article 8 of the Human Rights Act 1998: implications for clinical practice. Advances in Psychiatric Treatment 15: 23-31.

Curtice MJR (2009c) Medical treatment under Part IV of the Mental Health Act 1983 and the Human Rights Act 1998: review of Article 3 and 8 case law. Psychiatric Bulletin 33: 111-5.

De Burca G (1993) The principle of proportionality and its application in EC law. Yearbook of European Law 13: 105-50.

Department of Health (2008a) Human Rights in Health Care - A Framework for Local Action. Department of Health.

Department of Health (2008b) Code of Practice: Mental Health Act 1983. TSO (The Stationery Office) (http://www.dh.gov.uk/prod_consum_dh/ groups/dh_digitalassets/@dh/@en/documents/digitalasset/dh_087073. pdf).

Goldfeld AE, Mollica RF, Pesavento BH, et al (1988) The physical and psychological sequelae of torture: symptomatology and diagnosis. JAMA 259: $2725-9$

Gostin LO (2000) Human rights of a person with mental disabilities. International Journal of Law and Psychiatry 23: 125-59.

Hansard (2006) Mental Health Bill [HL]. Vol. 687, 28 November, cols. 656-7 (http://www.parliament.the-stationery-office.com/pa/ld200607/ Idhansrd/text/61128-0002.htm\#06112884000362).

Hendriks A (1995) Disabled persons and their right to treatment: allowing differentiation while ending discrimination. Health and Human Rights Journal 1: 152-74.

Joint Committee on Human Rights (2007) Legislative Scrutiny: Mental Health Bill. Fourth Report of Session 2006-07. HL Paper 40/HC 288. TSO (The Stationery Office). 
Kisely S, Campbell LA, Preston N (2005) Compulsory community and involuntary outpatient treatment for people with severe mental disorders. Cochrane Database of Systematic Reviews issue 3: CD004408.

Neufeldt AH, Mathieson R (1995) Empirical dimensions of discrimination against disabled people. Health and Human Rights Journal 1: 174-89.

Office of Public Sector Information (2007) Mental Health Act 2007. Amendments to the Mental Health Act 1983. OPSI (http://www.opsi. gov.uk/acts/acts2007/ukpga_20070012_en_1).

Ashingdane v. UK (1985) 7 EHRR 52.

Bensaid v. UK (2001) 33 EHRR 205

Dudgeon v. UK(1981) 4 EHRR 149

Grare v. France [1992] ECHR Application No.18835/91, 2nd December.

Guzzardi v. Italy (1980) 7367/76 ECHR 5

Herczegfalvy v. Austria (1992) 15 EHRR 437

HL v. UK (2004) 40 EHRR 761

HM v. Switzerland (2002) 38 EHRR 314

Hurtado v. Switzerland (1994) ECHR (Merits) Application No. 17549/90, 28th January.

Ireland v. UK [1978] 2 EHRR 25.

JE v. DE \& Ors [2006] EWHC 3459 (Fam).

Keenan v. UK [2001] 33 EHRR 38

Kolanis v. UK (2005) ECHR Application No. 517/02 21st June.

Kucheruk v. Ukraine (2007) ECHR Application No. 2570/04, 6th December.

L. v. Sweden (1988) ECHR Application No. 10801/84, 3rd October

Musiał v. Poland (2009) ECHR Application No. 28300/06, 20th January.
Nasri v. France (1995) ECHR Application No. 19465/92, 13th July; (1996) 21 E.H.R.R. 458

Nielsen v. Denmark (1988) 11 EHRR 175

Pilcic v. Croatia (2008) ECHR Application No. 33138/06, 17th January.

Pretty v. UK (2002) 35 EHRR 1.

$R$ (on the application of B) v. (1) Dr SS Responsible Medical Officer, Broadmoor Hospital (2) Dr G Second Opinion Appointed Doctor (3) Secretary of State for the Department of Health [2005] EWHC1936 Admin.

$R$ (on the application of H) $v$. Mental Health Tribunal (North and East London) [2002] QB 1

$R$ (on the application of KB and others) v. Mental Health Tribunal [2002] EWHC 639 (Admin).

$R$ (on the application of N) v. (1) Ashworth Special Hospital Authority (2) Secretary of State for Health [2001] EWHC 339 Admin.

$R$ (on the application of PS) v. (1) Responsible Medical Officer (Dr G) (2) Second Opinion Appointed Doctor (Dr W) [2003] EWHC 2335 Admin

$R$ v. Secretary of State for the Home Department, Ex Parte Daly [2001] 2 AC 532; [2001] UKHL 26.

Ribitsch v. Austria (1995) ECHR Application No. 18896/91, 4th December.

Sentges v. The Netherlands (2003) ECHR Application No. 27677/02, 8th July.

Smith \& Grady v. UK (1999) 29 EHRR 493

Storck v. Germany (2005) 43 EHRR 96

Tyrer v. UK (1978) ECHR Application No. 5856/72, 25th April.

Wilkinson v. UK [2006] ECHR Application No. 14659/02, 28th February.

Winterwerp $v$. The Netherlands [1979] 2 EHRR 387

X v. UK (1981) 4 EHRR 188
MCOs

Select the single best option for each question stem

1 With regard to the Human Rights Act 1998:

a it enacts all of the European Convention on Human Rights into UK law

b it is now UK statute enforceable by courts only

c it is now UK statute enforceable by mental health tribunals only

$d$ it has the effect of bringing human rights to the centre of the legal system only

e courts and mental health tribunals are obliged to interpret the Mental Health Act consistently with the Human Rights Act.

\section{With regard to Article 3 of the Human} Rights Act 1998:

a it is a qualified right

b it allows for exemptions for the public's health, safety or national security

c it is likely that a 'routine' CTO would infringe a patient's Article 3 rights

$\mathrm{d}$ authorities are under an obligation to protect the health of persons deprived of their liberty by providing requisite medical care

e medical treatment that is shown to be therapeutically necessary may be deemed inhuman or degrading.
3 With regard to Article 5 of the Human Rights Act 1998:

a case law has outlined two elements to defining a deprivation of liberty

b it is under Article 5(2) that detention on account of unsoundness of mind is allowed

c a patient may challenge a CTO through a mental health tribunal, but they are unable to challenge conditions attached to the order

d Article 5(4) does not entitle a person deprived of their liberty to have the lawfulness of their detention decided speedily by a court

e the dividing line between being deprived of liberty and restriction of movement is fact sensitive and easily discerned.

4 With regard to Article 8 of the Human Rights Act 1998:

a it consists of three parts

b it is an absolute right

c the concept of private and family life includes both physical and psychological integrity of a person

$d$ interferences with this right are permissible if they satisfy requirements outlined in Article 8(1)

e exceptions to Article 8 can be permitted when in 'accordance with law' or when 'necessary in a democratic society'.
5 As regards lawful review of detention under Article 5(4):

a a court does not need to be independent both of the executive and of the parties to the case

b the absolute minimum requirement is the right of an individual to present their own case and to challenge the medical and social evidence adduced in support of their detention

c a review does not need to allow a determination of the merits of the question as to whether the mental disorder persisted

$\mathrm{d}$ a person should have access to a court and the opportunity to be heard only through some form of representation

e only a cursory review of the merits of the associated medical decisions is necessary. 